Témoigner Témoigner. Entre histoire et mémoire

Getuigen Revue pluridisciplinaire de la Fondation Auschwitz

$122 \mid 2016$

Révisionisme et négationisme

\title{
Velibor Čolić, Ederlezi : Comédie Pessimiste
}

\section{Pierre Vaucher}

\section{(2) OpenEdition}

\section{Journals}

\section{Édition électronique}

URL : https://journals.openedition.org/temoigner/4703

DOI : 10.4000/temoigner.4703

ISSN : 2506-6390

\section{Éditeur :}

Éditions du Centre d'études et de documentation Mémoire d'Auschwitz, Éditions Kimé

\section{Édition imprimée}

Date de publication : 2 mai 2016

Pagination : 172-174

ISSN : 2031-4183

\section{Référence électronique}

Pierre Vaucher, «Velibor Čolić, Ederlezi : Comédie Pessimiste », Témoigner. Entre histoire et mémoire [En ligne], 122 | 2016, mis en ligne le 30 septembre 2021, consulté le 07 janvier 2022. URL : http:// journals.openedition.org/temoigner/4703; DOI : https://doi.org/10.4000/temoigner.4703

Ce document a été généré automatiquement le 7 janvier 2022.

Tous droits réservés 


\title{
Velibor Čolić, Ederlezi : Comédie Pessimiste
}

\author{
Pierre Vaucher
}

\section{RÉFÉRENCE}

Velibor Čolić, Ederlezi : Comédie Pessimite, Paris, Gallimard, 2014, 224 p.

1 Le 6 mai de chaque année, les Tsiganes des Balkans célèbrent l'arrivée du printemps à l'occasion de la fête de la Saint - Georges ou, en langue romani, Ederlezi. Ederlezi est aussi une chanson traditionnelle tsigane chantée pour la circonstance, qui fut adaptée pour le cinéma par le compositeur Goran Bregović. Le mot vient du turc Hidirellez, formé à partir du nom des prophètes Hizir Nebi et Hizir Ilyas (Élie). Selon une ancienne croyance anatolienne, les deux saints, le jour de leur rencontre sur terre, auraient atteint l'immortalité en buvant "l'eau de la vie" à une source demeurée secrète. Protecteur des voyageurs, venant par ailleurs au secours des pauvres, des opprimés et des personnes en danger, la figure mystique d'Hizir est restée associée au renouveau de la vie.

2 Le pari esthétique de Velibor Čolić est fort intéressant: rendre hommage à cette communauté singulière, elle aussi victime de l'extermination, en plaçant le récit historique sous l'égide d'un éternel retour qui, à la manière du cycle printanier, rappelle que tout finit par renaître, même l'amour et l'espérance. Ce n'est d'ailleurs pas un hasard si le roman Ederlezi est sous - titré " comédie pessimiste » : son principe est essentiellement comique, au sens shakespearien. Le livre s'ouvre ainsi sur une prosopopée, versant stylistique de la réincarnation : «Azlan Tcholero, Azlan Bahtalo et Azlan Chavaro Baïramovitch » - trois identités rom pour un seul destin - annonce luimême le récit de son cheminement sur terre, étendu sur trois vies complètes, depuis ce seuil ultime qu'est la mort du corps, topos bien connu d'un langage qui ne saurait être trahison. Le roman prend donc la figure d'un triptyque dont le principal fil conducteur, à la manière d'une musique gitane, est l'enchaînement tourbillonnant entre des 
énergies contraires, mais imbriquées l'une dans l'autre : l'humour et le drame, la joie de vivre et une misère omniprésente, l'aventure d'un orchestre à travers des temps et des lieux changeants et celle d'une persécution raciale tout aussi ubiquitaire, tout cela dans une prose a capella - un concert de voix. Cette posture littéraire, si elle donne un avantgoût de ces montagnes russes qu'est l'histoire des Tsiganes, force le lecteur à ne jamais tomber dans le tragique, abordant d'un œil serein certains rivages douloureux qui - il le devine bien - feront place à des temps meilleurs. À l'ouverture du premier volet de ce triptyque, un cadre est esquissé : c'est le village de Strehaïa, qui devient le point de fuite d'une longue fresque historique sur les peuples yougoslaves (à la façon du pont sur la Drina dans le roman d'Ivo Andrić); sa configuration, entre réalité et légende, rappelle justement que cette mémoire est innervée par un foisonnement de récits de la littérature orale. Comme issues de la rencontre des multiples destinées nomades ponctuant la chronique de Strehaïa, deux naissances sont annoncées: celle d'Azlan Tcholero, arrivé sur terre en Petit Poucet Balkan «avec des yeux qui ne se ferment jamais et qui produisent des larmes ", et celle de l'orchestre Ploska, prenant la route chaque printemps, après Ederlezi, pour se produire dans ce qui reste des ruines de vastes empires. C'est alors qu'un drame se tisse, par petites touches. Les péripéties burlesques de l'orchestre, entre beuveries, séductions féminines et nuitées «chez la police ", débouchent en effet sur un tournant imprévisible : celle du camp de Jasenovac (camp d'extermination créé par le régime des Oustachis). Azlan Tcholero et les autres membres de l'orchestre y seront anéantis. Mais, comme nous l'avons évoqué plus haut, le parti pris de Čolić est de permettre la métamorphose de cette mémoire du génocide tsigane par la force de la poésie. Dans le second volet du récit, Azlan Tcholero entame donc sa deuxième vie sous les traits d'un jeune homme dénommé Bahtalo, dont le parcours, comme un nouveau crescendo, produit un contrepoint aux images de l'anéantissement. Bien sûr, un autre orchestre reprend la route au printemps, cette fois sur les pistes de la Yougoslavie socialiste. Malgré les succès du début, les complications s'enchaînent encore plus vite qu'avant. À Belgrade, le nouveau Baïramovitch tombe amoureux d'une femme qui - comme toutes les autres, d'ailleurs - le perd: il sera arrêté par la police politique et envoyé dans un camp situé sur « l'île Nue » (allusion au goulag Goli Otok, où fut emprisonné le célèbre musicien Šaban Bajramović, dont le roman de Čolić est par ailleurs un hommage), afin de suivre une "rééducation communiste». Libéré au bout de trois ans, il voyage quelque temps en Europe de l'Ouest, avant de croiser la mort sur son chemin, sous les traits d'un soldat serbe qui le conduit au peloton d'exécution, à l'aube d'un autre conflit yougoslave. Le troisième volet ouvre le rideau pour une dernière représentation sur le théâtre du monde. La scène se déroule en France, cette fois-ci, où la figure du camp revient tel un éternel retour hivernal : c'est la jungle de Calais, avec ses réfugiés parqués dans des habitations précaires en attendant que les "taureaux d'acier " réalisent la ruine de leur brève résurrection. En écho au camp qui occupe maintenant tout l'espace narratif, le dernier Azlan Baïramovitch porte des cicatrices plus vieilles que lui et qui ne cessent de saigner. Il sera poignardé par un skinhead à l'occasion d'une triste «Döner Kebab Nacht ». On le voit, le cercle est bouclé. Mais le rideau se lèvera encore une fois devant tous les acteurs de cette farce: "Ils étaient bien vivants", rassemblés en une mystérieuse farandole, danse de la vie et de la mort.

3 L'ouvrage de Čolić reflète un choix ambitieux : reconstituer la mémoire d'un peuple oublié et apporter à ce témoignage, malgré les convulsions qui l'animent, les accents d'une fête de l'existence. Le contre - pied de cette entreprise est sans aucun doute la 
lenteur de l'action elle-même : par moments, le récit échoue à établir avec le lecteur ce contrat par lequel il va rester suspendu au dénouement. Il s'agit plutôt d'un récit opérant comme une rumeur. Le roman, en effet, ne cesse de puiser dans le fond diversifié des textes oraux: contes, proverbes, variantes drolatiques d'une même histoire et, bien sûr, une foule de personnages qui s'approprient et font circuler un imaginaire rebondissant. Mais la rumeur, c'est aussi cette parole décentralisée, dotée d'une grande force créatrice ; elle est à l'opposé de ces voix de l'ordre (grandes absentes de la chorale poétique, même si elles sont tapies dans l'ombre), qui souvent font tout déraper... 